\title{
Covid-19, global ethics, and Jihi: A voice from East Asian philosophy
}

\author{
EISUKE NAKAZAWA, AKIRA AKABAYASHI
}

\begin{abstract}
As the Covid-19 situation has developed rapidly into a pandemic of unprecedented scale, ethicists and philosophers must work to comprehend this tragic historical scene from a macroscopic perspective, striving to create peace in the minds of people worldwide. The Buddhist concept of Jihi is a key idea in East Asian philosophy and implies concern for others. Specifically, it requires its constituents to pray sincerely for the well-being and peace of mind of those who are suffering, regardless of nationality, age, gender, or family origin, and mourn this situation together. Accordingly, Jihi may represent a vital component of global ethics, particularly in situations involving the Covid-19 crisis.
\end{abstract}

Keywords: Covid-19, Jihi, Buddhism, global ethics

\section{Introduction}

Covid-19, first detected in Asia in December 2019, has rapidly become a pandemic of an unprecedented scale. In Japan, it began as an epidemic as cases of the coronavirus were confirmed among the passengers of the Diamond Princess cruise ship (1). Currently, as of December 2020, the country is teetering on the brink of explosive infection spread. Depletion of medical resources and exhaustion among medical practitioners are major issues worldwide, as each nation struggles to continue providing medical care to patients in severe conditions. One year ago, no one anticipated such a disastrous state worldwide.

Society is currently demanding insights from ethicists and philosophers on so many fronts. Grasping this tragic situation from a macroscopic perspective, ie, one which considers the entire human history, and then strives to create peace in the minds of those living through this horrific era, is truly the essential contribution required of philosophers.

\section{Jihi in Buddhism}

As secularised as Japan is as a society, the Japanese people may still subconsciously seek peace of mind during the Covid19 pandemic by turning to Buddhism, which originated in

Authors: Eisuke Nakazawa, (nakazawa@m.u-tokyo.ac.jp), Department of Biomedical Ethics, The University of Tokyo Faculty of Medicine, 7-3-1 Hongo, Bunkyo-ku Tokyo 113-0033 JAPAN; Akira Akabayashi, (akirasantky@umin.ac.jp), Department of Biomedical Ethics, The University of Tokyo Faculty of Medicine, 7-3-1 Hongo, Bunkyo-ku Tokyo 113-0033 JAPAN; Division of Medical Ethics, New York University, New York, USA.

To cite: Nakazawa, E., Akabayashi, A. Covid-19, global ethics, and Jihi: A voice from East Asian philosophy. Indian J Med Ethics. 2021 Apr-Jun; 6(2) NS: 138139. DOI: 10.20529/IJME.2020.126.

Published online first on November 26, 2020.

(C) Indian Journal of Medical Ethics 2020
India.

Buddha's Jihi is a key component of the overall Japanese mentality. Our trust in the world forms the foundation upon which we may embrace nature as it is. We place fundamental trust in the truthfulness, fairness, and infiniteness of the intellect that transcends self: this is Buddha's Jihi. Jihi is a concept introduced to Japan as an element that forms the basis of Buddhism. The characters 慈 ( $\mathrm{Ji}$ in Japanese, maitri in Sanskrit) and 悲 (Hi in Japanese, karuna in Sanskrit) represent the first two of the Four Immeasurables. Ji, which means loving-kindness or benevolence, signifies "a heart that longs to provide comfort to living things"; it means to love all things that have life and to seek peace and happiness and consider their interests at all times (2). Hi is a result of maitr, and is compassion; it signifies "a heart that desires to remove suffering from people." The latter character also encompasses a feeling of compassion for living things, which are subjected to various forms of physical and mental suffering. Jihi is Buddha's gaze that looks upon everything and everyone equally. There is no discrimination between old and young, or good and bad (3: Ch 1). As Jihi applies not only to human beings, the essence of Jihi also represents compassion, care, protection, and nurturing for all living things ( $3: \mathrm{Ch} 4)$.

The Pure Land faith is one of the key concepts of Buddhism. The Pure Land faith refers to the belief that a pure world can be sought by submitting oneself to the mercy of Buddha (Amithaba), by realising that we are powerless beings, and by acknowledging that this life filled with pain and endless suffering is awful. The very awareness that human beings are powerless leads one to rely on kami (Shinto gods), Buddha, fate, or nature; a greater power beyond the realm of human beings represents the philosophy underlying the Japanese view of the world that accepts nature as it is (4).

\section{Jihi and global ethics}

What are the expectations for global ethics during the current circumstances of the Covid-19 pandemic? We believe that one of the fundamental pillars of global ethics is sincere prayer for the well-being and peace of mind of those who are suffering, regardless of nationality, age, gender, or family origin, and mourning this situation together. This could be regarded as a request for global solidarity, or perhaps a request for global concern, much like 'Sorge' (care), as described by Heidegger (5).

The term "peace of mind" is not just synonymous with "lack of worry" or "calmness." Rather, it has a more positive and normative meaning. From the perspective of Buddhist thought, and using philosophical/phenomenological terminology, it would be said that the phenomenal is the horizontal, but at the same time, the horizontal is the phenomenal. In addition, "peace of mind" can mean calmness 
or a lack of worry within an individual's mind, as well as that within the whole world. Genuine peace of mind in an individual is achieved when peace for the whole world is sought. Jihi describes the relationship between such individuals who have achieved genuine peace of mind and the whole world.

Most other countries or regions likely have similar ideologies to the Buddhist concept of Jihi. For example, the Christian concept of "charity" and the Confucian concept of "Ren (Jin)" (6) are both similar to Jihi in Buddhism. It is beyond the scope of the present paper to use comparative religious studies methodology to compare and contrast these three concepts; however, as a fairly standard representative of most Japanese individuals -in other words, as one who does not subscribe to a particular faith but lives out their daily life in the mosaic comprising secularised religion-my intuitive description of the differences between the three concepts would be as follows. The Christian concept of "charity" has, at its base, the request to "Love your neighbour." Specifically, "Love your neighbour" would imply that we should draw close to all the people we have ever met, sharing their sorrows and praying with them. The objective of charity seems to be aimed at individual and specific human beings. Meanwhile, the Buddhist concept of Jihi has a more general target, in that it is more of a lens through which all people are to be viewed. The Confucian concept of Ren (Jin, or humanity or humaneness) actually differs by whether it is the Ren of Confucius or that of the Confucian philosopher, Mencius (6). However, the basis of this concept seems to be rooted in the relationships within a family (that between a parent and child, or sibling relationships). Within the Buddhist Jihi concept, the concept of "hi" not only expresses compassion, but also implies "sadness (悲 しさ )," particularly in Japanese. It seems to me, therefore, that the Buddhist concept of Jihi finds its particular uniqueness in the fact that one views all living beings across the world equally through this lens of sadness.

Religious customs in Japan are, arguably, quite interesting. We celebrate births with Shinto*, consecrate marriages using Christian traditions, and mourn deaths as Buddhists. At first glance, the Japanese view of religion seems unconventional and incongruous. However, one remarkably common belief throughout Japan is that Buddhism is linked to death. Covid19 has heightened the awareness of death among Japanese people, leading the latter to allow Buddhist ideas to form the basis of our thinking. In other words, we Japanese tend not to confine ourselves to the limits of local ethics. We feel that this openness exhibited toward different cultures is a positive aspect of the Japanese culture. This sort of multiculturally symbiotic way of thinking is critically important in times when the world is facing danger, and especially now that our everyday lives are threatened by the Covid-19 virus. If ideas such as Jihi are bringing about peace to people in Asia, then similar wisdom may also offer the same benefit to those in other regions. Similar teachings and ideas can come together as one, slowly amalgamating into a notion that surrounds the entire planet as we struggle to work our way through this crisis. This amalgamation of ideas worldwide should be one common objective for global ethics in this time.

\section{Conclusions}

In today's world, as Covid-19 continues to spread, global ethics can provide peace of mind for people around the world and ease their suffering even a little. To this end, Jihi is a concept that could be incorporated into global ethics in Asia. We sincerely hope that the Covid-19 pandemic will trigger the maturation of global ethics, in terms of bringing together loosely connected teachings and ideas similar to Jihi from around the world to form an amalgamation of ideas that could save mankind.

\section{Note}

*Shinto is a Japanese traditional religion. It is animistic and has a creation myth.

\section{References}

1. Nakazawa E, Ino EH, Akabayashi. A. Chronology of COVID-19 cases on the Diamond Princess Cruise ship and ethical considerations: A report from Japan. Disaster Med Public Health Prep. 2020 Mar 24 (2000):1-8: doi: 10.1017/dmp.2020.50.

2. Ngrjuna (transl. Kumrajva). Da zhidu lun. [Japanese]. Date unknown [cited 2020 Aug 6].T1509_.25.0208c08-10. Available from: https:// 21dzk.l.u-tokyo.ac.jp/SAT/ddb-sat2.php? mode $=$ detail\&mode $2=1 \&$ num $1=1509 \&$ num $2=\&$ vol $=25 \&$ page $=0208$

3. Yuien. Tannisho. Transl. Unno T. Date unknown [cited 2020 Aug 6]. Available from: https://web.archive.org/web/20121018113404/http:// www.livingdharma.org/Tannisho/TannishoChaptersl-X.html.

4. Nakazawa E, Yamamoto K, Ozeki-Hayashi R, Akabayashi A. A global dialogue on withholding and withdrawal of medical care: an East Asian perspective. Am J Bioeth. 2019 Mar 19; 19(3): 50-2. Doi: 10.1080/15265161.2018.1563650.180-230

5. Heidegger M. Sein und Zeit. [Being and Time].Tübingen: Max Niemeyer Verlag. 1967. pp. 180-230. [German].

6. Wong D. Chinese ethics. In: Zalta EN, editor. The Stanford Encyclopedia of Philosophy (Summer 2020 Edition). Available from: https:// plato.stanford.edu/archives/sum2020/entries/ethics-chinese/.

\title{
Be a part of IJME
}

IJME invites readers to submit research studies, comments, case studies, reports, reviews, letters, as also poems, short stories, original paintings and photographs of print quality ( both in colour and B/W ) to be considered for publication.

\author{
All submitted matter is subject to peer review.
}

Contributors are neither paid nor charged any fee for published matter. 